Greenberg (1957) did not alter the ratio of protein to radioactivity.

When the two isomers of the ${ }^{14} \mathrm{C}$-labelled anilinopropionamide were supplied separately to the tissue, a similar amount of binding was observed in each case.

If this binding to proteins is by a normal peptide bond this would mean that with the herbicidal isomer of the anilinopropionamide a derivative of D-alanine is incorporated into protein. This could cause inhibition of subsequent protein synthesis. With the non-herbicidal isomer a derivative of the naturally occurring L-isomer of alanine would be incorporated. This may not interfere with the normal mechanism of protein synthesis.

Further work is being carried out to elucidate the precise effect of 2-(4-methyl-2,6-dinitroanilino)- $\mathrm{N}$ methylpropionamide on the mechanism of protein synthesis in plants (Baxter \& Weeks, 1971).

Baxter, R. \& Weeks, D. P. (1971) Proc. Symp. Nucleic Acids and Proteins in Higher Plants Tihany (in the press)

Peterson, A. E. \& Greenberg, D. M. (1957) Methods Enzymol. 4, 708

Yates, J. (1968) Proc. Brit. Weed Contr. Conf. 9th. 2, 659

\section{Studies on the L-Serine $\boldsymbol{O}$-Sulphate-Degrading Activity of Pig Liver}

By N. Tudball and P. Thomas (Department of Biochemistry, University College, Cathays Park, Cardiff CF 1 1XL, U.K.)

An enzyme system that catalyses the $\alpha \beta$-elimination of $\mathrm{L}$-serine $O$-sulphate has now been obtained from pig liver in a homogeneous form (Tudball et al., 1971). The system is unique in that it does not require the obligatory participation of pyridoxal phosphate as a cofactor (Tudball et al., 1969). It has a limited specificity, acting only on $N$-terminal serine $O$ sulphate residues and on $\beta$-chloro-L-alanine (Thomas $\&$ Tudball, 1967). The substrates normally employed for enzyme assay have not yet been shown to occur in Nature. and it seems unlikely that the normal function of the system is associated with these compounds.

To obtain more information on the true function of the enzyme and its mode of action, the features of the L-serine $O$-sulphate molecule that are necessary for binding and catalytic activity were investigated. To this end an initial assumption was made that the conformation adopted by the substrate in the crystal form (N. Tudball, J. P. G. Richards \& H. Davies, unpublished work) resembled to a high degree that form of the substrate in solution normally interacting with the enzyme.

By using the extended-chain crystal form of L- serine $O$-sulphate as a model, it was predicted from stereochemical considerations that cyclic compounds related to isophthalic acid would act as reversible competitive inhibitors of the enzyme. A large number of compounds possessing the desired properties were tested and found to be good competitive inhibitors, the degree of inhibition varying with the nature of substituent groupings.

Attempts at varying the basic L-serine $O$-sulphate structure with a view to promoting substrate-like properties generally proved unsuccessful, though it is now possible to define those features of the molecule necessary for activity. Any potential substrate must possess an electronegative $\beta$-substituent, either a $-\mathrm{Cl}$ grouping or an $-\mathrm{OSO}_{3}{ }^{-}$grouping. The hydrogen atom attached to the $\alpha$-carbon cannot be replaced and the $\alpha$-amino grouping must be present in an unmodified form.

The implications of the above results will be discussed.

P. T. is grateful to the Science Research Council for a Studentship.

Thomas, J. H. \& Tudball, N. (1967) Biochem. J. 105, 467

Tudball, N., Thomas, J. H. \& Fowler, J. A. (1969) Biochem. J. 114, 299

Tudball, N., Thomas, P. \& Bailey-Wood, R. (1971) Biochem. J. 121, 747

Separation of the Adenosine $3^{\prime}$-Phosphate 5'-Sulphatophosphate-Degrading Enzymes of Bovine Liver

By W. H. B. Denner, A. M. Stokes and K. S. DoDGson (Department of Biochemistry, University College, P.O. Box 78, Cardiff CF1 $1 X L$, U.K.)

The tissues of a variety of species have been shown to possess enzymes which degrade adenosine 5'sulphatophosphate and adenosine 3'-phosphate 5'sulphatophosphate (Brunngraber, 1958; Balasubramanian \& Bachhawat, 1962; Adams, 1964; Austin et al., 1969; Armstrong et al., 1970; Koizumi et al., 1969; Farooqui \& Balasubramanian, 1970; BaileyWood et al., 1969, 1970). Some of the observations on adenosine $3^{\prime}$-phosphate $5^{\prime}$-sulphatophosphate degradation have been made with relatively crude enzyme systems and long incubation periods. Under these conditions it is not easy to distinguish between the production of ino ganic sulphate by $(a)$ direct desulphation of adenosine $3^{\prime}$-phosphate $5^{\prime}$-sulphatophosphate by an adenosine 3 '-phosphate 5 '-sulphatophosphate sulphohydrolase and the sequential action of (b) a 3'-nucleotidase, forming adenosine 